\title{
Thermochemical properties and glass forming tendency modeling for the ternary Ge-Mn-Gd melts
}

\author{
Natalia V. Kotova*, Natalia I. Usenko, Natalia V. Golovata \\ Department of Chemistry, Taras Shevchenko National University of Kyiv, Volodymyrska Street, \\ 64/13, Kyiv 01601, Ukraine \\ nkotova61@gmail.com
}

Keywords: germanium, manganese, gadolinium, enthalpy of mixing, glass forming tendency.

Information on the thermochemical properties may be useful for predicting of the concentration regions of easy glass formation in multicomponent alloys. In present investigation the integral enthalpies of mixing for the Ge-Mn-Gd melts were determined for the entire concentration interval at $1830 \mathrm{~K}$ using the Redlich-Kister-Muggianu method. GFT values for binary and ternary alloys of this system were calculated. Size mismatch entropy was estimated within the frameworks of hard spheres model. On the basis of performed calculations the concentration regions in which the melts of the Ge-Mn-Gd system can demonstrate considerable tendency to easy glass formation were suggested.

\section{Introduction}

Rare earth intermetallic compounds in ternary RE-Mn-Ge systems (where RE - rare earth metal), in particular GdMnGe, $\mathrm{GdMn}_{2} \mathrm{Ge}_{2}$, $\mathrm{Gd}_{3} \mathrm{Mn}_{4} \mathrm{Ge}_{4}$ and $\mathrm{GdMn}_{6} \mathrm{Ge}_{6} \quad[1-5]$, attract considerable attention due to their unusual electronic and magnetic properties. Such compounds can exhibit antiferromagnetic type of ordering with subsequent transition to a ferromagnetic, paramagnetic or even ferromagnetic state under the influence of a temperature or magnetic field, or when a certain part of the compound atoms is replaced by atoms of some other $d-$ and f-metals. The abovementioned properties of these intermetallics make them promising for use as magnetic materials. Special mention should be made about magnetic properties of amorphous materials obtained from liquid alloys of the $\mathrm{Ge}-$ Mn-Gd system [6]. Therefore, information on the thermochemical properties as well as prediction of the concentration region where easy glass formation can be observed in the $\mathrm{Ge}-\mathrm{Mn}-$ Gd system may be useful for the purposes of production of amorphous magnetic materials.

Previously, in [7] we have presented the results of the calorimetric experiments for the liquid alloys of the five sections with constant $x_{\mathrm{Ge}} / x_{\mathrm{Mn}}$ ratio equal to $0.25 / 0.75,0.4 / 0.6$, $0.5 / 0.5,0.7 / 0.3$ and $0.8 / 0.2$ of the Ge-Mn-Gd system at $1830 \mathrm{~K}$. In the present work we have used the Redlich-Kister-Muggianu method of 
modeling of thermodynamic properties of the ternary alloys to determine the concentration dependence of integral enthalpies of mixing throughout the whole concentration triangle. The data on the thermochemical properties of binary constituent systems and those of the $\mathrm{Ge}-\mathrm{Mn}-\mathrm{Gd}$ ternary system, experimentally obtained within a limited concentration region, have been used for this purpose. The term of specific "ternary" interaction has been determined in order to obtain the best fit of the simulated data with the experimental ones.

To calculate the thermochemical properties of the ternary $\mathrm{Ge}-\mathrm{Mn}-\mathrm{Gd}$ alloys, we used the data on the enthalpies of mixing of liquid alloys for the binary constituents systems obtained via high-temperature calorimetry, an experimental technique which allows to obtain the most reliable data on the enthalpies of mixing. It should be noted that the data available in the literature up to 2006 are rather completely analyzed in [7]. Since then, three new works have appeared on the properties of constituent binary systems of interest, namely: Ref. [8] on the experimental determination of the enthalpies of mixing in the Gd-Mn system, the 2017 assessment [9] on the same system, and the 2014 assessment [10] on the Ge-Mn system. After thorough analysis of the abovementioned sources, we selected the data that most adequately describe the enthalpies of mixing in the constituent binary systems at high temperature, namely: the data from Ref. [11] obtained at $1585 \mathrm{~K}$ for the Ge-Mn system (according to [7] and [10]); the data from Ref. [12] obtained at $1973 \mathrm{~K}$ for the Ge-Gd system (according to [7]); the data from Ref. [8] at 1650 $\mathrm{K}$ for the Gd-Mn system (according to [9]). While performing calculations we considered it possible to neglect the temperature dependence of the enthalpies of mixing at such a high temperature.

It should be noted that the data on the enthalpies of mixing of liquid alloys for the binary constituent systems correlate well with their phase diagrams. All three binary phase diagrams demonstrate a significant number of intermediate phases of fixed composition or with extended homogeneity range. The minimum value of the integral enthalpy of mixing $\left(\Delta_{\text {mix }} H\right.$ ) in the $\mathrm{Ge}-\mathrm{Mn}$ alloys is equal to $(-20.9) \mathrm{kJ} \mathrm{mol}^{-}$ ${ }^{1}$ and is observed at $x_{\mathrm{Mn}}=0.65$ [11]. According to the Ge-Mn phase diagram [10] a series of chemical compounds exists in the same composition region $\left(x_{\mathrm{Mn}}=0.6 \div 0.8\right)$. For the liquid alloys of the $\mathrm{Ge}-\mathrm{Gd}$ system the minimum $\Delta_{\text {mix }} H$ reaches $(-98.4) \mathrm{kJ} \mathrm{mol}^{-1}$ at $x_{G e}=0.45$ [12]. Such a great exothermic effect combined with the existence of a series of the hightemperature solid compounds including congruently melting $\mathrm{Gd}_{5} \mathrm{Ge}_{3}$ in the same composition region [13] allows concluding existence a short-range order of a chemical compound type in a liquid state. The Gd-Mn system is characterized by small negative values of the enthalpy of mixing (with the minimum 
$\Delta_{\text {mix }} H$ value of $(-2.0) \mathrm{kJ} \mathrm{mol}^{-1}$ at $\left.x_{\mathrm{Mn}}=0.6\right)$ [8].

According to the phase diagram of this system [14], three intermetallic compounds with low melting temperatures (below the melting point of the manganese) exist in Mn-rich composition region.

The calculations of the enthalpies of formation for the ternary system were performed according to the Redlich-Kister-Muggianu formula, which is given by the following equation:

$$
\begin{aligned}
& \Delta H\left(x_{1}, x_{2}, x_{3}\right)=x_{1} x_{2} \sum_{i=0}^{n} L_{\mathrm{Me} 1-\mathrm{Me} 2}\left(x_{1}-x_{2}\right)^{i}+ \\
& +x_{1} x_{3} \sum_{i=0}^{n}{ }^{i} L_{\mathrm{Me} 1-\mathrm{Me} 3}\left(x_{1}-x_{3}\right)^{i}+ \\
& +x_{2} x_{3} \sum_{i=0}^{n} L_{\mathrm{Me} 2-\mathrm{Me} 3}\left(x_{2}-x_{3}\right)^{i}+ \\
& +x_{1} x_{2} x_{3}\left(x_{1}^{0} L_{\mathrm{Me} 1-\mathrm{Me} 2-\mathrm{Me} 3}+\right. \\
& \left.+x_{2}{ }^{1} L_{\mathrm{Me} 1-\mathrm{Me} 2-\mathrm{Me} 3}+x_{3}{ }^{2} L_{\mathrm{Me} 1-\mathrm{Me} 2-\mathrm{Me} 3}\right),
\end{aligned}
$$

where ${ }^{i} L_{\mathrm{Me} 1-\mathrm{Me} 2},{ }^{i} L_{\mathrm{Me} 1-\mathrm{Me} 3},{ }^{i} L_{\mathrm{Me} 2-\mathrm{Me} 3}$ are the coefficients of the Redlich-Kister polynomial for the corresponding binary systems, $n$ is the power of this polynomial, ${ }^{0} L_{\mathrm{Me} 1-\mathrm{Me} 2-\mathrm{Me} 3},{ }^{1} L_{\mathrm{Me} 1-\mathrm{Me} 2-\mathrm{Me} 3}$, ${ }^{2} L_{\mathrm{Me1}-\mathrm{Me} 2-\mathrm{Me} 3}$ are the ternary interaction parameters.

The Redlich-Kister parameters for the binary systems were obtained by conversion of the corresponding simple polynomials for the binary constituent systems into the RedlichKister polynomials. The last term of the equation (1) characterizes the specific ternary interaction which is a measure of deviation of the thermodynamic properties of ternary solution from the regular behavior. It is important to know this term to better understand the nature of the component interaction in liquid state. The ternary parameters were obtained as a result of the statistical treatment of the difference between the experimental data for the ternary system and those calculated from the regular solution model.

\section{Results and discussion}

The complete set of binary and ternary parameters is listed in Table $\mathbf{1 .}$

\begin{tabular}{|c|c|c|c|}
\hline \multirow{2}{*}{${ }^{i} L_{\mathrm{Mel}-\mathrm{Me} 2}$} & \multicolumn{3}{|c|}{$\mathrm{Me}_{1}-\mathrm{Me}_{2}$ system } \\
\hline & $\mathrm{Mn}-\mathrm{Ge}$ & $\mathrm{Ge}-\mathrm{Gd}$ & $\mathrm{Gd}-\mathrm{Mn}$ \\
\hline${ }^{0} L_{\mathrm{Me} 1-\mathrm{Me} 2}$ & $\begin{array}{c}- \\
73.103\end{array}$ & -387.698 & -7.528 \\
\hline${ }^{1} L_{\mathrm{Me} 1-\mathrm{Me} 2}$ & $\begin{array}{c}- \\
72.948\end{array}$ & 102.108 & 5.117 \\
\hline${ }^{2} L_{\mathrm{Me} 1-\mathrm{Me} 2}$ & 20.693 & 29.923 & 3.438 \\
\hline${ }^{3} L_{\mathrm{Me} 1-\mathrm{Me} 2}$ & 58.069 & - & -4.184 \\
\hline${ }^{4} L_{\mathrm{Me} 1-\mathrm{Me} 2}$ & -3.470 & - & -1.530 \\
\hline${ }^{5} L_{\mathrm{Me} 1-\mathrm{Me} 2}$ & $\begin{array}{c}- \\
21.142\end{array}$ & - & 0.997 \\
\hline${ }^{i} L_{\mathrm{Me} 1-\mathrm{Me} 2-\mathrm{Me} 3}$ & \multicolumn{3}{|c|}{ Ge-Mn-Gd system } \\
\hline${ }^{0} L_{\mathrm{Mel}-\mathrm{Me} 2-\mathrm{Me} 3}$ & \multicolumn{3}{|c|}{-386.345} \\
\hline${ }^{1} L_{\mathrm{Me} 1-\mathrm{Me} 2-\mathrm{Me} 3}$ & \multicolumn{3}{|c|}{289.476} \\
\hline${ }^{2} L_{\mathrm{Me} 1-\mathrm{Me} 2-\mathrm{Me} 3}$ & \multicolumn{3}{|c|}{38.210} \\
\hline
\end{tabular}

Table 1. The binary and ternary interaction parameters for the integral enthalpies of mixing $\Delta_{\text {mix }} H$ $\left(\mathrm{kJ} \cdot \mathrm{mol}^{-1}\right)$ in liquid alloys of the binary $\mathrm{Ge}-\mathrm{Mn}(\mathrm{Gd})$, $\mathrm{Mn}-\mathrm{Gd}$ and ternary Ge-Mn-Gd systems at $1830 \mathrm{~K}$

The projections of the obtained isoenthalpies of mixing of the ternary Ge-MnGd melts in the entire Gibbs concentration triangle are shown in Figure 1. It should be noted that for the binary $\mathrm{Gd}-\mathrm{Ge}$ melts in the composition range of $0.25<x_{\mathrm{Ge}}<0.55$ (in the vicinity of the existence of high-melting binary 
compounds) as well as for the ternary alloys with compositions close to the same region the enthalpies of mixing refer to the supercooled liquid state of the alloy. In our opinion, this should not significantly affect the results of subsequent calculations, due to the fact that usually the temperature dependence of the exothermic values of the enthalpies of mixing at sufficiently high temperatures is insignificant.

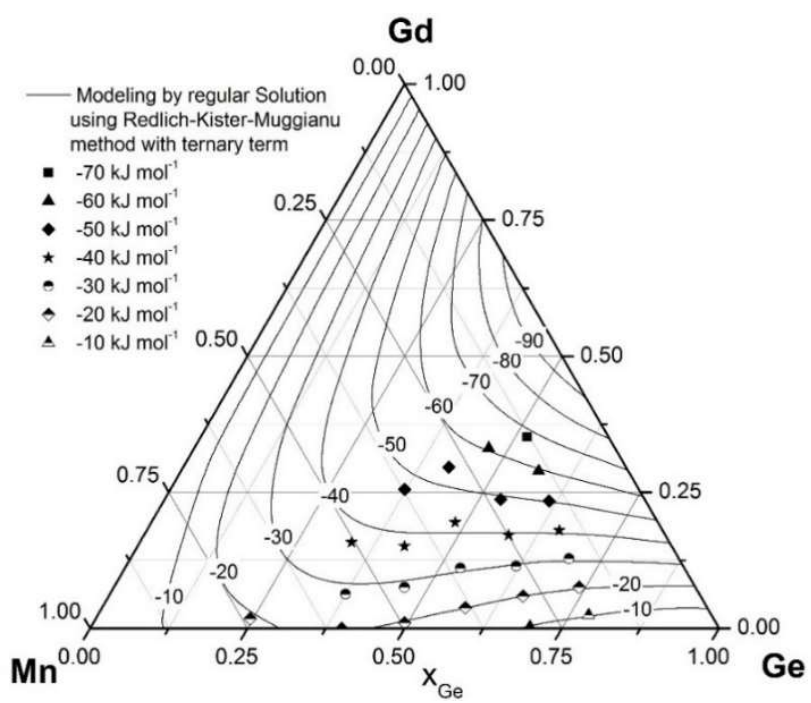

Figure 1. The projections of isolines of the integral enthalpies of mixing of the ternary Ge-Mn-Gd alloys at $1830 \mathrm{~K}\left(\mathrm{~kJ} \cdot \mathrm{mol}^{-1}\right)$ in comparison with experimental values (individual characters, indicated in figure) obtained for this ternary system [7]

From Figure 1 one can see that the $\Delta_{\text {mix }} H$ surface in this system gradually decreases from the Mn-rich corner to the $\mathrm{Ge}-\mathrm{Gd}$ side of the concentration triangle. The minimum value of the enthalpy of mixing of the ternary liquid alloys at the composition close to those of the most stable intermetallics in the Ge-Gd system. The topology of the isolines also indicates the effect of the short-range order that exists in the Ge-Mn system at $x_{M n}>0.7$ on the properties of ternary melts that are close in composition to this binary system.

The simulation of the glass forming tendency of the Ge-Mn-Gd liquid alloys. One of the actual problems of materials science is to perform an estimation of the tendency of certain metal alloy to form glass when rapidly cooling from the liquid phase and to assess the thermodynamic stability of such glass to recrystallization. Of course, it is desirable to evaluate these properties quantitatively, basing on simple criteria and calculations. It is well known, that this problem has both thermodynamic and kinetic aspects. The thermodynamic stability of an amorphous phase with respect to pure components can be considered as a necessary condition for an amorphous alloy formation if the kinetic requirements to formation and growth of nuclei of a crystalline phase are satisfied. One can say that thermodynamic properties determine the general possibility of formation of a disordered amorphous state instead of a stable crystalline state [15]. The thermodynamic properties of supercooled liquid and amorphous alloys at the glass forming temperature $\left(T_{\mathrm{g}}\right)$ are very similar. Therefore, the extrapolation of the thermodynamic properties of liquid alloys to the glass transition temperature $T_{\mathrm{g}}[16]$ can be used to estimate the thermodynamic aspects of amorphous alloys formation in a wide range of compositions, including those for which amorphous alloys have not yet been obtained 
experimentally. It may be important for assessing the prospects of the formation of new amorphous materials and also the conditions of their exploitation.

Interparticle interaction determines the structure and thermodynamic properties of metal alloy in a liquid state. Therefore, the possibility of metal glass obtaining through the rapid quenching of liquid alloy is also determined by the interaction between atoms of different components. The existence of ordered groups of atoms or atomic associates in the bulk of liquid melt substantially affects its tendency to amorphization. In some cases, the existence of such associates may lead to an increase in glass formation tendency due to the extension of the period of time necessary to rearrange the shortrange order inherent in liquid state to that inherent in solid state. In other cases, the similar atomic groups can act as the centres of crystallization.

At the present time the number of methods is used for assessing the ability to easy amorphization. Some of them take into account the peculiarities of the metallic melts (such as the presence of deep eutectics, the ability to significant overcooling of the liquid phase, etc.) another base on their thermodynamic properties (such as great negative enthalpies or free energies of mixing), that makes the estimation much more reliable.

The authors of Ref. [17], basing on the kinetic theory of the nucleation and growth of crystals, and taking into account the strong interaction between different kinds of atoms, which contributes to the formation of associates (or clusters, in their terminology) and to the changes in diffusion coefficients of atoms of components in melts, proposed the application of the GFT (glass forming tendency) criterion, which determines the tendency for easy glass formation. GFT can be calculated as follows:

$$
\begin{aligned}
& G F T=-\lg \left(1-2 \frac{c H_{\mathrm{AB}}^{m}}{c_{m} R T_{\mathrm{g}}}\right)-0.434 \frac{c H_{\mathrm{AB}}^{m}}{c_{m} R T_{\mathrm{g}}}- \\
& -0.145\left(\frac{c}{c_{m}}\right)^{m+n} \ln \left(\frac{N}{m+n}\right),
\end{aligned}
$$

where $T_{\mathrm{g}}$ is the absolute temperature, to which it is possible to overcool the liquid alloy; $R$ is the universal gas constant; $m$ and $n$ are the stoichiometric coefficients of the associate (cluster or binary complex); $H_{\mathrm{AB}}^{m}-$ enthalpy of formation of liquid melt at $c_{m}=n /(m+n)$ concentration, $N$ - Avogadro number. In this form, GFT is the ratio of the tendency of a binary solution to form glass to the same value of the pure component A. GFT demonstrates how much easier and faster can be certain alloy converted into amorphous state as compared to the pure component in the same conditions of rapid quenching. The alloy of the selected composition forms a metallic glass easily than the pure component if the GFT value is greater than zero. Although the model is approximate, the predictions based on it are in good agreement 
with many experimental results, as shown in $[18$, 19].

The model presented in [17] was used to determine the glass formation tendency for the binary constituent $\mathrm{Ge}-\mathrm{Mn}(\mathrm{Gd}), \mathrm{Mn}-\mathrm{Gd}$ systems and the ternary Ge-Mn-Gd systems. It was assumed that the glass formation temperature was $0.6 T_{\mathrm{m}}$ of the component with the lowest melting point, that is $730 \mathrm{~K}$ (for $\mathrm{Ge}-\mathrm{Mn}(\mathrm{Gd})$ ) and $910 \mathrm{~K}$ (for $\mathrm{Mn}-\mathrm{Gd}$ ). When choosing the composition of the clusters that influence the formation of the amorphous phase the most, we have taken the cluster of composition that corresponds to a congruently melting compound with the highest melting temperature or to a compound that forms the eutectic of the lowest temperature. Input data for GFT calculations in the binary constituent systems of the Ge-Mn-Gd ternary system are presented in Table 2. The type of the cluster has been determined according to the phase diagrams of the corresponding binary systems.

Table 2. Cluster compositions for the binary Ge-Mn(Gd) and $\mathrm{Mn}-\mathrm{Gd}$ constituent systems

\begin{tabular}{|c|c|c|}
\hline System & $\begin{array}{c}\text { Variants of } \\
\text { considered systems }\end{array}$ & $c_{m}=\frac{n}{m+n}$ \\
\hline $\mathrm{Ge}-\mathrm{Mn}$ & $\begin{array}{c}\mathrm{Ge}-\mathrm{Mn}: \mathrm{Ge}-\mathrm{Ge}_{3} \mathrm{Mn}_{5} \\
\mathrm{Mn}-\mathrm{Ge}: \mathrm{Mn}- \\
\mathrm{Mn}_{5} \mathrm{Ge}_{3}\end{array}$ & $\begin{array}{l}0.625 \\
0.375\end{array}$ \\
\hline $\mathrm{Gd}-\mathrm{Mn}$ & $\begin{array}{l}\text { Gd-Mn: Gd-GdMn } \\
\text { Mn-Gd: Gd--Mn } 2 \text { Gd }\end{array}$ & $\begin{array}{l}0.667 \\
0.333\end{array}$ \\
\hline $\mathrm{Ge}-\mathrm{Gd}$ & $\begin{array}{l}\text { Ge-Gd: } \mathrm{Ge}-\mathrm{Ge}_{3} \mathrm{Gd}_{5} \\
\text { Gd-Ge: } \mathrm{Gd}-\mathrm{Gd}_{5} \mathrm{Ge}_{3}\end{array}$ & $\begin{array}{l}0.625 \\
0.375\end{array}$ \\
\hline
\end{tabular}

We have corrected the formula (2) for the GFT calculation proposed by the authors [17] taking into account that we use the exact values of the integral enthalpies of mixing $\left(\Delta_{\text {mix }} H(x)\right)$ of the melts according to the experimentally obtained concentration dependences, but not the approximate values of the enthalpies recalculated from the cluster formation enthalpy, i.e. $\frac{c}{c_{m}} H_{\mathrm{AB}}^{m}=\Delta_{\text {mix }} H(x)$. After simple mathematical transformations, we obtained the following equation (3) for GFT calculation:

$$
\begin{aligned}
& G F T=-0.434\left\{\ln \left(1-2 \frac{\Delta_{\text {mix }} H(x)}{R T_{g}}\right)+\frac{\Delta_{\text {mix }} H(x)}{R T_{g}}\right\}- \\
& -0.145\left(\frac{c}{c_{m}}\right)^{m+n} \ln \left(\frac{N}{m+n}\right) .
\end{aligned}
$$

The GFT concentration dependences for the binary Ge-Mn (Gd) and Mn-Gd constituent systems calculated by equation (3) are presented in Figure 2.

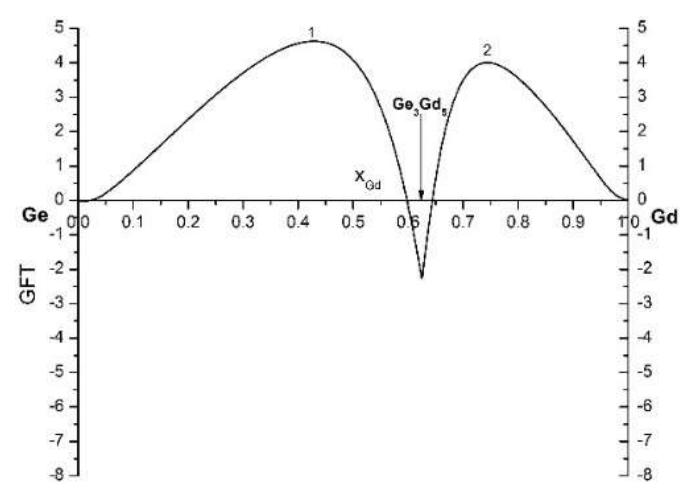

a) 


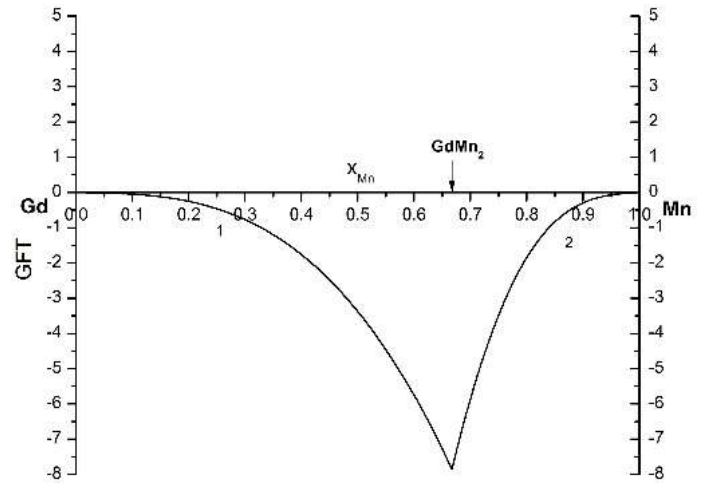

b)

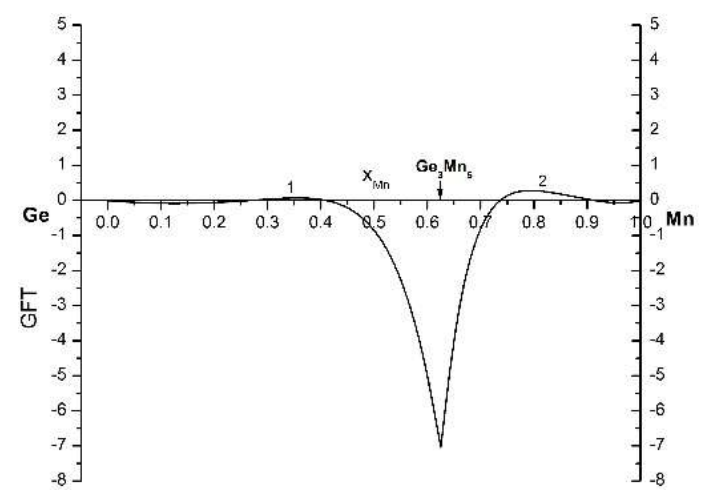

c)

Figure 2. Composition dependences of GFT for liquid alloys of the binary constituent Ge-Mn (Gd) and Mn-Gd systems.

Figure 2,a demonstrates a strong tendency for easy glass formation in the Ge-Gd melts in comparison with pure germanium and gadolinium. According to our results two areas of easy glass formation can be expected: the first one is in concentration range from nearly pure germanium to $x_{\mathrm{Gd}}=0.6$ and the second is from $x_{\mathrm{Gd}}=0.64$ up to nearly pure gadolinium. Calculations were performed for the most likely $\mathrm{Gd}_{5} \mathrm{Ge}_{3}$ cluster because it corresponds to the most thermally stable compound in this system and thus can provide the best results in predicting the areas of easy glass formation for this system. According to our calculations for the $\mathrm{Mn}-\mathrm{Gd}$ alloys (Figure 2,b), we do not observe any tendency for easy glass formation as compared with pure components. It means that to obtain glass in this system, it is necessary to apply cooling rates not less, maybe higher, than that for obtaining glass from pure liquid Mn or Gd. From Figure 2,c one can see that for the Ge-Mn alloys the tendency to easy glass formation is insignificant. The region of an easy amorphization of liquid alloys as compared to the pure components is rather narrow and is located in the Mn-rich composition range. In this system, GFT calculations were performed for $\mathrm{Mn}_{5} \mathrm{Ge}_{3}$ cluster, because according to the phase diagram of the Ge-Mn system the melting temperature of such an intermetallic is the highest of those existing in this system, so it can be expected that the best result is achieved when applying this composition of the cluster.

For the calculations in the ternary GeMn-Gd we have assumed that the composition of the clusters which affect the tendency for easy amorphization varies gradually along the line connecting the compositions of $\mathrm{Mn}_{5} \mathrm{Ge}_{3}$ and $\mathrm{Gd}_{5} \mathrm{Ge}_{3}$ binary compounds (the most thermally stable in the corresponding binary systems). This is a reasonable assumption, especially taking into account that the $\mathrm{Mn}_{5} \mathrm{Ge}_{3}$ and $\mathrm{Gd}_{5} \mathrm{Ge}_{3}$ binary compounds are isostructural. Therefore, along the $\mathrm{Mn}_{5} \mathrm{Ge}_{3}-\mathrm{Gd}_{5} \mathrm{Ge}_{3}$ section of the ternary Ge$\mathrm{Mn}-\mathrm{Gd}$ system, a series of $\mathrm{X}_{5} \mathrm{Ge}_{3}$ associates may be formed, where $\mathrm{X}$ denotes manganese and gadolinium atoms taken in different ratios close 
to the ratio of their concentrations in the corresponding ternary alloy. The validity of such approach is confirmed by the existence of the ternary $\mathrm{Gd}_{3} \mathrm{Mn}_{2} \mathrm{Ge}_{3}$ compound, which was established in [20] (Figure 3). Figure 3 also demonstrates that the great majority of ternary compounds in Ge-Mn-Gd system have compositions close to the line connecting $\mathrm{Gd}_{5} \mathrm{Ge}_{3}$ and $\mathrm{Mn}_{5} \mathrm{Ge}_{3}$ compounds.

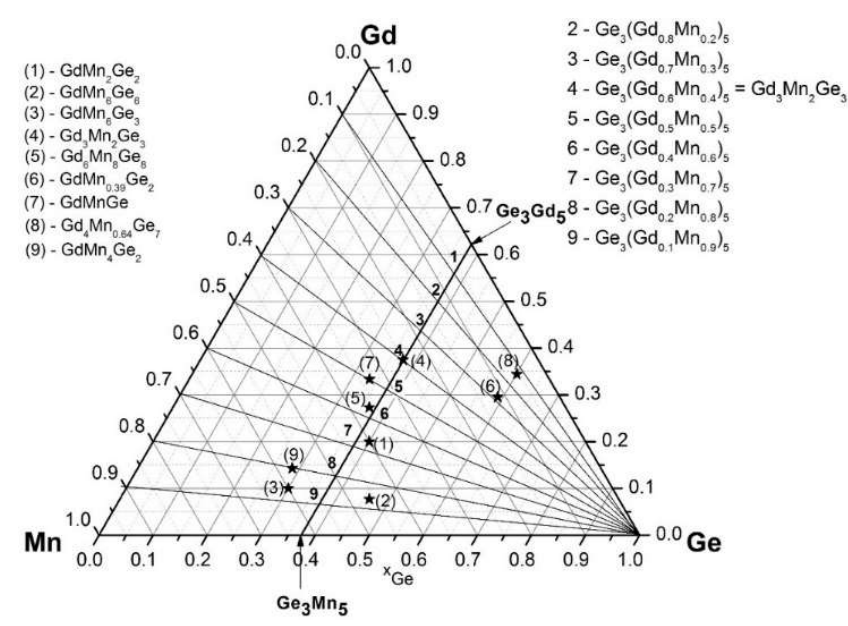

Figure 3 - Scheme explaining the calculations of GFT of the ternary $\mathrm{Ge}-\mathrm{Mn}-\mathrm{Gd}$ alloys; asterisks and numbers in parentheses correspond to the compositions of ternary compounds determined at $973 \mathrm{~K}$ in [20].

GFT was calculated for the germaniumrich alloys for which the mixing enthalpies were obtained experimentally as well as for the gadolinium-rich alloys that were not calorimetrically investigated, but the reliable values of integral enthalpies of mixing for them were obtained due to calculation of ternary interaction term.

For the ternary Ge-Mn-Gd alloys the glass formation temperature $T_{\mathrm{g}}$ was chosen to be $730 \mathrm{~K}$.
The results obtained for the GFT values of the ternary $\mathrm{Ge}-\mathrm{Mn}-\mathrm{Gd}$ alloys are presented in Figure 4.

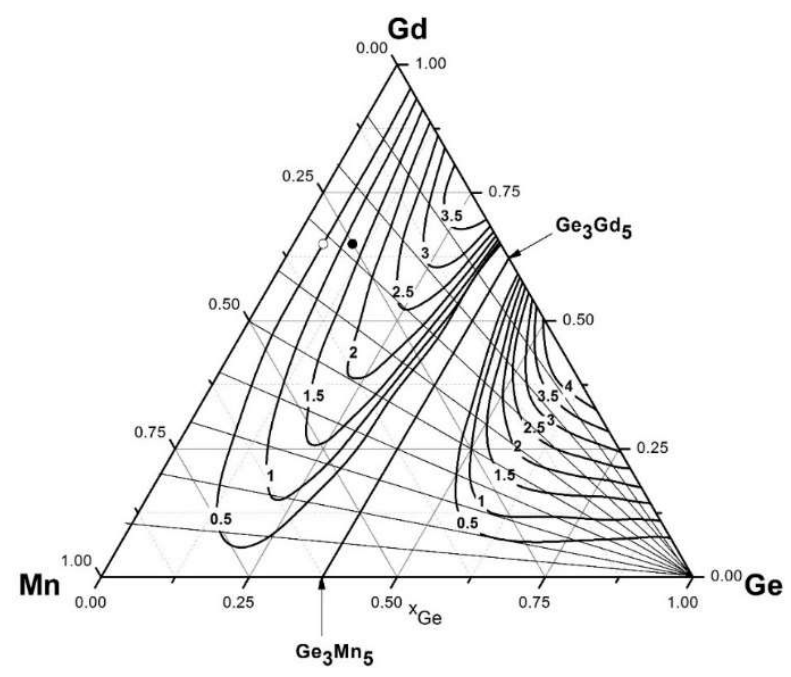

Figure 4. Projections of GFT isolines of the ternary GeMn-Gd melts. The compositions of the alloys for which amorphous ribbons have been experimentally obtained in [6] are given for comparison: $\bigcirc-\mathrm{Gd}_{65} \mathrm{Mn}_{30} \mathrm{Ge}_{5}$; $\mathrm{Gd}_{65} \mathrm{Mn}_{25} \mathrm{Ge}_{10}$.

Figure 4 demonstrates that the largest positive value of GFT is expected for the alloys with compositions close to the Ge-Gd binary system. With increase in a content of manganese the GFT value is gradually decreases for the alloys of the both parts of concentration triangle, situated to the right and to the left of the line connecting $\mathrm{Gd}_{5} \mathrm{Ge}_{3}$ and $\mathrm{Mn}_{5} \mathrm{Ge}_{3}$ compounds. For the alloys located inside the areas defined by lines with GFT $=2$ one can expect that the glass formation for the ternary Ge-Mn-Gd alloys proceeds much easier than for pure germanium or gadolinium.

In addition, it should be noted that the considered ternary system is not only the one with strong interaction of components in liquid state, but also is characterized by large size 
difference of the components. Indeed, according to the data [21] on the radii of the first coordination sphere for metallic melts the radii of component atoms are: $r_{\mathrm{Mn}}=133 \mathrm{pm}, r_{\mathrm{Ge}}=141$ $\mathrm{pm}, r_{\mathrm{Gd}}=183 \mathrm{pm}$. The combination for the GeMn-Gd ternary alloys of such characteristics as large exothermic enthalpies of mixing and large component size mismatches may further evidence in favour of the existence of sufficiently wide concentration regions of alloys with easy amorphization in this system.

Within the framework of the liquid state model, known as hard spheres model, which is widely used for the description of metallic melts, the difference between the atomic sizes of the alloy components always leads to the appearance of a positive entropy contribution to the thermodynamic functions of the formation of a disordered phase, the so-called size mismatch entropy $S_{\sigma}[22,23]$. According to the approach of the authors of [24], such a positive contribution is favourable to the appearance of areas of easy amorphization. So, for our ternary system we have calculated the corresponding $S_{\sigma}$ contribution to the entropy of mixing. The calculations of $S_{\sigma}$ values were carried out according to the following equation:

$$
\begin{aligned}
& S_{\sigma} / k_{\mathrm{B}}=\frac{3}{2}\left(\varsigma^{2}-1\right) y_{1}+\frac{3}{2}(\varsigma-1)^{2} y_{2}- \\
& -\left\{\frac{1}{2}(\varsigma-1)(\varsigma-3)+\ln \varsigma\right\}\left(1-y_{3}\right),
\end{aligned}
$$

where $k_{\mathrm{B}}$ is the Boltzmann constant, the $\varsigma$ parameter is related to the sphere packing coefficient $\xi$ as $\varsigma=1 /(1-\xi)$, the coefficient of packing in our calculations was equal to 0.64 , that corresponds to the random packing of hard spheres in the amorphous phase according to [24]. Dimensionless parameters $y_{1}, y_{2}$ and $y_{3}$ were determined using the data on diameters $d_{i}$ of hard spheres and molar fractions $x_{i}$ of the corresponding components according to the following equations (taking into account that

$$
\begin{gathered}
\left.y_{1}+y_{2}+y_{3}=1\right): \\
y_{1}=\frac{1}{\sigma^{3}} \sum_{j>i=1}^{3}\left(d_{i}+d_{j}\right)\left(d_{i}-d_{j}\right)^{2} x_{i} x_{j} \\
y_{2}=\frac{\sigma^{2}}{\left(\sigma^{3}\right)^{2}} \sum_{j>i=1}^{3} d_{i} d_{j}\left(d_{i}-d_{j}\right)^{2} x_{i} x_{j} \\
y_{3}=\frac{\left(\sigma^{2}\right)^{3}}{\left(\sigma^{3}\right)^{2}} \\
\sigma^{k}=\sum_{i=1}^{3} c_{i} d_{i}^{k} ; k=2,3 .
\end{gathered}
$$

The isolines of the obtained $S_{\sigma} / k_{\mathrm{B}}$ values for the ternary Ge-Mn-Gd system plotted in the concentration triangle are shown in Figure 5 (solid lines).

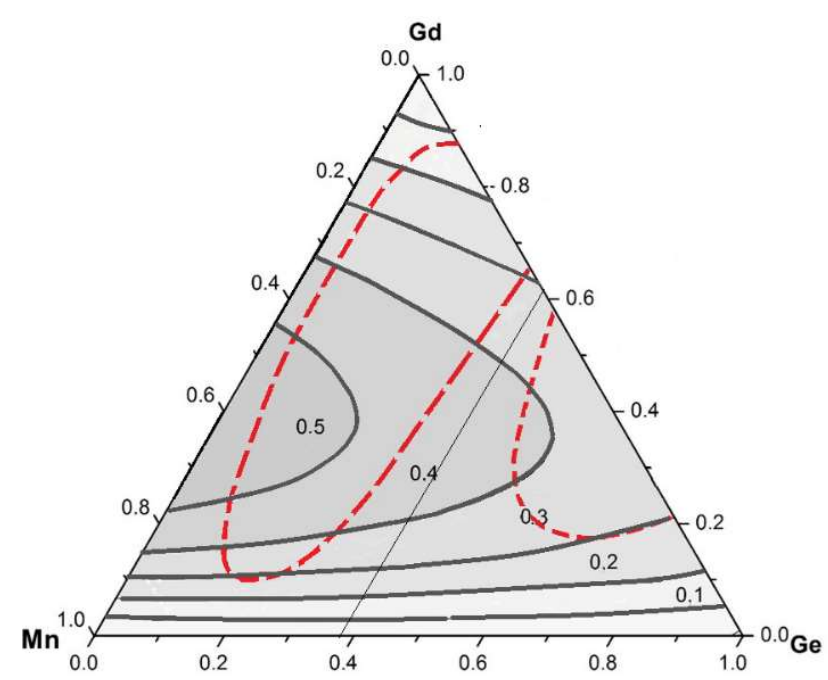


Figure 5. Projections of the isolines of $S_{\sigma} / k_{\mathrm{B}}$ parameter for the Ge-Mn-Gd system (solid lines) and the expected regions of easy formation of the amorphous alloys (dashed lines).

Comparison of the topology of $S_{\sigma} / k_{\mathrm{B}}$ and $\Delta_{\text {mix }} H$ surfaces with the results of the performed GFT calculations allows to reasonably assume that the concentration regions of alloys with the high tendency to amorphization are situated inside the dashed contours, as shown in Figure 5. The first of these dashed contours almost completely coincides with the isoline with GFT $=0.5$ for alloys located to the left of the $\mathrm{Ge}_{3} \mathrm{Mn}_{5}-\mathrm{Ge}_{3} \mathrm{Gd}_{5}$ connecting line, and the second coincides with the isoline with the GFT $=1.5$ for alloys located to the right of this line. For the alloys whose compositions lie along the indicated curves, despite the relatively small values of the GFT parameter ( 0.5 or 1.5$)$, an additional positive effect on the formation of the amorphous phase is provided by the size mismatch entropy $S_{\sigma} / k_{\mathrm{B}}$ factor, whose value is more than 0.3 in the vicinity of the maximum of the curvature of the indicated GFT curves. The value of $S_{\sigma} / k_{\mathrm{B}}>0.3$ can contribute to the additional thermodynamic stabilization of the disordered liquid phase. It also can contribute to the formation of the amorphous phase by increasing the period of time necessary for rearrangement of the short-range order inherent in liquid state to that inherent in the crystalline phase of the corresponding composition. It should be noted that the compositions of the amorphous alloys obtained by rapid quenching in [6] fall into the indicated regions (see Figure 4). The composition of the compounds (8) and (6) from Figure 3 also fall into the region of easy amorphization, which means that one can expect to obtain these magnetic phases in amorphous state.

\section{Conclusions}

The integral enthalpies of mixing for the Ge-Mn-Gd melts were determined for the entire concentration interval at $1830 \mathrm{~K}$ using the Redlich-Kister-Muggianu method and taking into account the term of a specific ternary interaction. This made possible to calculate the GFT values for the alloys of the binary Ge$\mathrm{Mn}(\mathrm{Gd})$ and $\mathrm{Mn}-\mathrm{Gd}$ constituent systems and of the ternary Ge-Mn-Gd system and to suggest the concentration regions in which the melts can demonstrate great tendency to easy glass formation when being rapidly cooled. In the ternary system, these regions are located on both sides of the line which connects the compositions of the $\mathrm{Ge}_{3} \mathrm{Mn}_{5}$ and $\mathrm{Ge}_{3} \mathrm{Gd}_{5}$ compounds. Also, the calculations of the size mismatch entropy $S_{\sigma}$ were performed since this ternary system refers to the type of systems with strong component interaction in liquid state and with large atomic size difference of the components. The significant value of $S_{\sigma}$ can contribute to the appearance of wide areas of easy amorphization for the alloys of the Ge-Mn-Gd ternary system. 


\section{References}

[1] Morozkin AV, Seropegin YuD, Sviridov IA. Crystallographic data of new ternary TiNiSi (Co2Si)-type $\mathrm{RMnGe}(\mathrm{R}=\mathrm{Sm}, \mathrm{Gd}, \mathrm{Dy}-\mathrm{Tm})$ compounds. J. Alloys Comp. 1998; 269: L1-L5.

[2] Narasimhan KSVL, Rao VUS, Bergner RL, Wallace WE. Magnetic properties of $\mathrm{RMn}_{2} \mathrm{Ge}_{2}$ compounds ( R = La, Ce, Pr, Nd, Gd, Tb, Dy, Ho, Er and Th). J. Appl. Phys. 1975; 46(11): 4957-4960.

[3] Kobayashi H, Onodera H, Yamamoto H. Magnetic properties of single crystal GdMn2Ge2 in high magnetic field. J. Magnetism and Magnetic Materials. 1989; 79(1): 76-80.

[4] Szytuła A, Wawrzyńska E, Penc B, Stüsser N, Tomkowicz Z, Zygmunt A. Magnetic properties and electronic structure of R3T4X4 (R: La-Nd, Gd-Er; T: Mn, Cu; X: Ge, Sn) compounds. J. Alloys Comp. 2004; 367(1-2): 224-229.

[5] Duijn HGM, Brück E, Buschow KHJ, de Boer FR. Electrical resistivity of RMn6Ge6 $(\mathrm{R}=$ rare earth $)$ compounds. J. Magnetism and Magnetic Materials. 1999; 197: 691-693.

[6] Zhong XC, Min JX, Zheng ZG, Liu ZW, Zeng DC. Critical behavior and magnetocaloric effect of $\mathrm{Gd}_{65} \mathrm{Mn}_{35-\mathrm{x}} \mathrm{Ge}_{\mathrm{x}}(\mathrm{x}=0,5$, and 10) melt-spun ribbons. J. Appl. Phys. 2012; 112: 033903.

[7] Kanibolotsky DS, Kotova NV, Bieloborodova OA, Lisnyak VV. High temperature calorimetric examination of mixing in liquid (gadoliniumgermanium-manganese) alloys. J. Chem. Thermodyn. 2006; 38: 849-860.

[8] Ivanov M, Berezutski V, Usenko N. Mixing enthalpies in liquid alloys of manganese with the lanthanides. Int. J. Mat. Res. (formerly Z. Metallkd.). 2011; 102(3): 277-281.

[9] Wang J, Lin Sh, Rong M, Rao G, Zhou H. Experimental investigation and thermodynamic reassessment of the Mn-Gd binary system. J. Therm. Anal. Calorim. 2017; 128(2): 1009-1018.
[10] Berche A, Tedenac JC, Jund P. Thermodynamic modeling of the germanium - manganese system. Intermetallic. 2014; 47: 23-30.

[11] Geld PV, Petrushevsky MS, Yesin YuO, Gorbunov YuV. Jental'pii obrazovanija i struktura blizhnego porjadka zhidkih splavov marganca $\mathrm{s}$ kremniem, germaniem i olovom. Dokl. Akad. Nauk SSSR. 1974; 217: 1114-1117.

[12] Kanibolotsky DS, Golovata NV, Bieloborodova OA, Lisnyak VV. High temperature calorimetric study of liquid (gallium-gadolinium-germanium) alloys. J. Chem. Thermodyn. 2005; 37: 117-129.

[13] Okamoto H. Gd-Ge (Gadolinium-Germanium). J. Phase Equilibria and Diffusion. 2012; 33(2): 163.

[14] Kim J, Jung I-H. Thermodynamic modelling of $\mathrm{Mn}-\mathrm{Y}$ and Mn-Gd systems for application of RE in $\mathrm{Mg}$ alloy development. Canadian metallurgical quarterly. 2013; 52(3): 311-320.

[15] Kim YK, Soh JR, Kim HS, Lee HM. Thermodynamic prediction of glass forming range in Al-Mg-REM ternary system. Calphad. 1998; 22(2): 221-230.

[16] Turchanin AA, Turchanin MA, Agraval PG. Thermodynamics of undercooled liquid and amorphous binary metallic alloys. Metastable and Nanocrystalline Materials. 2001; 10: 481-486.

[17] Zielinski PG, Matyja H. Influence of liquid structure on glass forming Tendency. Paper presented at: Rapidly Quenched Metals Sec. Int. Conf.; Cambridge, MIT Press, 1975. p. 237-248

[18] Witusiewicz VT. Thermodynamic properties of liquid alloys of $3 \mathrm{~d}$ transition metals with metalloids (Silicon, Carbon and Boron). J. Alloys Compd. 1994; 203: 103-116.

[19] Witusiewicz VT. Thermodynamics of binary and ternary melts of the $3 \mathrm{~d}$ transition metals $(\mathrm{Cr}, \mathrm{Mn}$, $\mathrm{Fe}, \mathrm{Co}$ and $\mathrm{Ni}$ ) with boron. Thermochim. Acta. 1995; 264: 41-58.

[20] Markiv VJa, Biloborodova OA, Beljavina NM, Aleksє€va NV. Izotermichnij pereriz diagrami 
stanu sistemi Ge-Mn-Gd pri $700^{\circ} \mathrm{S}$. Dopovidi AN Ukraïni. 1993; 7: 70-73.

[21] Ostrovskij OI, Grigorjan VA, Vishkarev AF. Stroenie metallicheskih rasplavov. Moskva: Metallurgija; 1988.

[22] Mansoori GA, Carnahan NF, Starling KE, Leland TW. Equilibrium Thermodynamic Properties of the Mixture of Hard Spheres. J. Chem. Phys. 1971; 54: 1523-1525.

[23] Singh P, Khanna KN. Entropy of mixing calculations for compound forming liquid alloys in the hard sphere system. Physica B+C. 1984; 124(3): 369-374.

[24] Takeuchi A, Inoue A. Calculations of Mixing Enthalpy and Mismatch Entropy for Ternary Amorphous Alloys. Materials Transactions, JIM. 2000; 41(11): 1372-1378. 